Ruth Derksen, UNIVERSITY OF BRITISHCOLUMBIA, ruth.derksen@ubc.ca

\title{
Think, Read, and Write
}

\author{
A Review of Critical Reading in Higher Education: Academic Goals and Social Engagement \\ by Karen Manarin, Miriam Carey, Melanie Rathburn, and Glen Ryland
}

As instructors, regardless of the discipline, we often tell students: "think critically, write critically, and read critically." Yet we rarely clarify or guide students in understanding these rhetorical actions. The authors' central purpose for writing this publication is clear. They are conducting an extensive investigation of "critical reading" by asking a central question: How do students in first-year general education classes read critically? Their motivation is to enhance students' abilities to not only read texts, but also to be inspired to effectively engage in the world as a result of their reading. This publication is based on instructors' findings in a study conducted at Mount Royal University in Calgary, Alberta, Canada.

The authors challenge the common presupposition that students understand how to read for academic purposes and that they share their instructors' understanding. However, if they do not, then a common assumption the authors observe is that students just need to spend more time reading a particular text. Yet, critical reading is not commonly understood. The authors go on to define this kind of reading as comprehension, analysis, interpretation and evaluation.

The authors' objectives for this study are comprehensive and practical: 1 . To share information grounded in recent research about reading processes and intellectual development. 2. To describe how students read. 3. To offer suggestions to improve students' reading, believing that reading can be taught in an under-graduate curriculum. 4. To encourage instructors to consider larger questions and clarify the purpose of critical reading. 5. To enable a conversation about critical reading between instructors ( $\mathrm{p}$. xii).

The publication contributes explicitly to the scholarship or teaching and learning as a field. The authors cite a 2014 Scholarship or Teaching and Learning conference along with other collaborative ventures that involve students and instructors investigating the implications of their research and teaching activities. Significantly, the authors make it clear that this study is a collaborative venture. They hope to inspire others to engage is similar activities of sharing their insights, rather than working in isolation.

More specifically, the authors explain that they decided to conduct a methodical and collaborative investigation into critical reading because without such an in-depth examination, it would be difficult to assess engagement and improvement over the years. The result is a publication in the form of a stand-alone book rather than a journal article (or several). By publishing in this particular genre, the authors hope that the study will be examined more closely and assessed more seriously in forthcoming years.

The primary, intended audience for this collaborative venture is teachers and scholars of critical reading. The authors explain that "faculty from different disciplines and institutions may find our discussion of reading behaviors in different first-year classes illuminating” (p. xi). Specifically, critical 
reading is explored in four differing fields in which the authors are immersed: History, Biology, English, and Political Science.

However, faculty members in other fields who do not necessarily perceive themselves as teachers of reading are also encouraged to become engaged. These readers are not directly addressed, but the authors believe that they have a vested interest in the outcome of effective critical reading. This broader audience could potentially provide challenges that might create confusion. However, the authors' collaboration in diverse disciplines results in an effective and comprehensive understanding of how students can benefit from critical reading in a concrete way rather than being given abstract concepts with vague applications.

As an overview, Chapter One examines a wider application (or "generalizability") of the data gathered from the four disciplines represented by the authors. They hope to appeal not only to Canadian readers, but to American and British educational systems. The data gathered includes 700 documents in various written genres that reflect students' reading and comprehension. Rubrics have been designed and are explained in this chapter (The appendixes offer rubrics and material used in this study, but also include a helpful "Coda" that assesses the lessons learned during the collaborative experience.) The authors, somewhat surprisingly, find more similarities than differences between the various disciplines they examine.

Chapter Two queries one of the authors' central concerns, Can students read? In order to address the question, students' ability to comprehend, analyze, interpret and evaluate are examined. Some positive findings in students' comprehension are found, but these are minimal. Common assumptions held by faculty are also examined in that they could possibly impede students' success in critical reading.

Chapter Three assesses the effects of genre on students as they engage in the critical reading process. Although the authors focus particularly on recognition of genres and their integration, the research essay becomes the central concern. Such a topic is useful in understanding students' and instructors' attitudes toward the research essay, but misses a significant opportunity to examine genre as a shaping device. Students' recognition of a genre is stressed, but the authors do not draw enough attention to the interconnectedness of genre, audience and purpose. Whether students read logs, newspaper articles or research papers, they need to be aware of genre differences, of the audience the document is directed toward and of the overall purpose of the article, log or research paper. Oblique references are made about a possible audience of a reading log, but much more attention could be given to the triadic relationship of genre, audience and purpose. I suggest an addition to the last statement made under "Lessons Learned" at the end of the chapter: "Emphasizing the intellectual process of reading, including the role genre [purpose and audience] plays in understanding, rather than the technical details of the final product can facilitate critical reading for academic purposes" (p. 64). Chapter Four investigates the effects of social engagement and personal experience on the process of critical reading. The authors express astonishment that, regardless of the discipline, students exhibit an absence of social engagement in writing despite the often provocative issues being discussed in an assigned reading. Although the authors examine students' assumptions and encourage comprehensive activities, the study finds that students in all disciplines did not engage socially and pragmatically in their academic research papers; however, they did engage in much more passionate and socially embedded responses in their personal reflection paper. A helpful proposal in this regard is the author's recommendation that students become more actively involved in civic and social events as a way of enabling more meaningful engagement. But a caveat is warranted here. Instructors' assumptions 
about students' knowledge of "civic and social events" described in assigned readings should be examined more closely. Who are these students engaging in the assigned readings? Millennials? From Alberta only? From the prairie provinces of Canada? Or are they American students? Even the locations of East Coast or West Coast will shape students' perceptions of civic and social events; even more so international students from numerous countries. The assigned readings themselves most likely contain a predisposition toward an instructors' knowledge of the world and would not always be reflective of actual student experience or cultural milieu.

Chapter Five is a reflection of knowledge gained from this study and the implications of that knowledge. This chapter provides an assessment of the process of collecting data and interacting with students. The chapter then leads to specific observations of the "needs" of undergraduate students that the authors claim are useful for any instructor, regardless of the discipline or the institution. Again, sociocultural environments inform all reading and writing activities, thus more specific identification of institutions and their location cannot be ignored. But overall, the authors promote honest inquiry for all classrooms and institutions and hope that their study will result in moving from "lamentation to action". Although several deficits have been mentioned in this review, and further discussion would enhance the publication, the approach of the authors needs to be applauded. This study and the resulting publication is not one individual's ego project. It is a collaborative inquiry that has only one end goal-to improve undergraduate students' engagement in critical reading.

Ruth Derksen (PhD) is Professor Emeritus of communication courses in the Faculty of Applied Science at the University of British Columbia.

Copyright for the content of articles published in Teaching \& Learning Inquiry resides with the authors, and copyright for the publication layout resides with the journal. These copyright holders have agreed that this article should be available on open access under a Creative Commons Attribution License 4.0 International (https://creativecommons.org/licenses/by/4.0). The only constraint on reproduction and distribution, and the only role for copyright in this domain, should be to give authors control over the integrity of their work and the right to be properly acknowledged and cited, and to cite Teaching \& Learning Inquiry as the original place of publication. Readers are free to share these materials - as long as appropriate credit is given, a link to the license is provided, and any changes are indicated. 